\title{
CHEMICAL CHARACTERIZATION OF SUB-BITUMINOUS COAL FROM THE ARAUCO PROVINCE - CHILE
}

\author{
PAOLA MÉNDEZ ${ }^{a}$, CAMILA RIVERA $^{a}$, CESAR PINO $^{a}$, RODOLFO MUNDACA ${ }^{b}$, \\ ROSARIO CASTILLO ${ }^{b}$, JOSÉ NEIRA ${ }^{b}$, CARLOS PEÑA-FARFAL ${ }^{a, b}{ }^{*}$
}

${ }^{a)}$ LABEL, Laboratory of Biosensors \& Electroanalysis, School of Pharmacy, University of Concepcion, Barrio Universitario SN, 4070043 - Concepcion, Chile
b) Department of Instrumental Analysis, School of Pharmacy, University of Concepcion, Barrio Universitario SN, 4070043 - Concepcion, Chile

ABSTRACT

The chemical and sorptive characteristics of mineral coals extracted from a mine in Lebu (Biobío Region, Chile) and its derivatives were studied. These derivatives were obtained by applying a thermal treatment in an environment with $\mathrm{N}_{2}$ and $\mathrm{CO}_{2}$ at different experimental conditions, in order to increase their specific surface. In addition, coals were characterized by using proximal analysis, elementary analysis and petrographic analysis. In order to know their structure and surface, Boehm titration analysis, FTIR infrared spectroscopy, X-ray diffraction and scanning electron microscopy were performed. The surface of the selected carbons was modified by selectively oxidizing it with $\left(\mathrm{NH}_{4}\right)_{2} \mathrm{~S}_{4} \mathrm{O}_{8}$ and with $\mathrm{H}_{2} \mathrm{O}_{2}$ e impregnating with an iron solution for the study with $\mathrm{H}_{2} \mathrm{O}_{2}$ In the oxidation of $\mathrm{H}_{2} \mathrm{O}_{2}$, the work was carried out at different $\mathrm{pH}$. The results show a moderate homogeneity between different types of seams studied, whereas when coals are treated with heat or strong oxidants, increases its surface and can be used with analytical applications (v.g. electroanalytical sensors).

Keywords: Arauco mineral coal, FTIR, Boehm tritation, oxidation surface, SEM.

\section{INTRODUCTION}

Coals can be defined as sedimentary heterogeneous rocks in terms of their organic (macerals) and inorganic (minerals) composition, formed millions of years ago from plant material. Coal is the most abundant fossil resource in the world. The Energy International Agency (EIA) estimates that there are reserves of about 100 billion tons. distributed in over 70 countries [1]. In Chile, coal deposits are located in different areas, mainly in the provinces of Concepcion, Arauco, Valdivia and Magallanes.

Deposits from lignite coal to bituminous coal are widely distributed. These sedimentary basins of Paleocene-Neocene are located in the coastal plains and in the continental shelf in the occidental side of the Andean mountains [1,2]. In total, these three basins are home to approximately 1.2 billion metric tones of coal reserves. Given the magnitude of the Chilean coal resources and taking into account the historical and current rates of coal production, it is estimated that the existing reserves will last more than 100 years in the future [2].

Arauco basin in Central Southern Chile (Fig. 1) contains a number of bituminous and sub-bituminous coals in Eocene strata. It is estimated that its production represents five million metric tones [3].

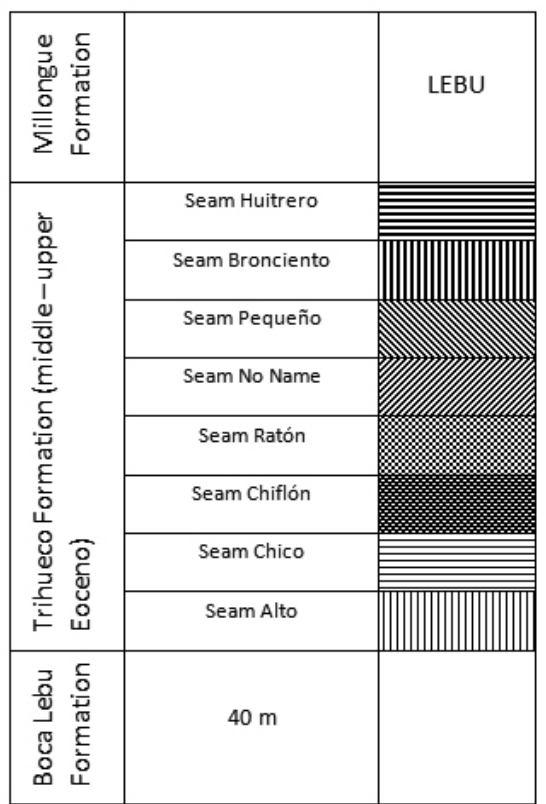

Figure 1: Generalized Stratigraphic columns for the different coal basins in the Lebu. Adaptation from [3].
Currently, in Chile there is a low consumption of national coal, as well as a poor generation of economic instances aimed to the consolidation of a coal industry. This trend contradicts with the international mentality, where countries rich in coal are generating new technologies around the carbochemical industry, thanks to the fabrication of products with great added value [4]. Coal is consumed in Chile mostly for the generation of electricity.

Any material with high carbon content, has great chance to be transformed into highly porous material. In fact, mineral coal, wood and coconut shells are the most common material in the production of activated carbon worldwide. About a third of the world production of activated coal is obtained from bituminous mineral coal and more than $50 \%$ of the world production of activated coal from China and the United States uses mineral coal as raw material [5].

Many application of the activated carbon materials are strongly influenced by their surface chemistry. The high content of heteroatoms such as nitrogen or oxygen provides to the material a series of acid, basic or oxide-reducing features [6].

Different textural and chemical properties of the carbon materials and their electrochemical properties have been studied for several applications, such as ultracapacitors and carbon paste electrodes with different analytical applications [7-9]. Studies that used activated carbons of different origins, have proved to be very useful in the manufacturing of carbon paste electrodes from highly functionalized activated carbons [10], as well as in the preparation of biosensors that use carbon paste [11]. These electrodes have different analytical applications, including an environmental use [12]. In recent years the interest on the application of carbons as electrodes has increased. Despite this fact, in Chile there are no studies related to find added value to the coal from the Arauco area, a very economically depressed sector despite its richness in both forest and coal industry. Thus, the present study is the starting point to search for new application of coal in areas different from energy.

This study is aimed to give an added value to the mineral coal from the Arauco area and to characterize minerals of bituminous and sub-bituminous type by means of different analytical techniques, to obtain a qualitative view of their chemical structure.

\section{EXPERIMENTAL}

\subsection{Reagents and materials}

Sub-bituminous coals coming from Mantos Negros mine. Located in the Lebu city, Arauco Province, Biobío Region of Chile, were studied. The coal seams were: Huitrero seam (HS), alto seam (AS), Chico seam (CHS), Bronciento seam (BS) and Raton seam (RS).

Different coal samples were milled and sieved, and the fraction of $100 \mathrm{um}$, was used for analysis.

All solutions were prepared using $18.2 \mathrm{M} \Omega \mathrm{cm}$ deionized water from a aquaMAXTM Ultra 370 Series Ultra Water Purification System (Young Lin, Seoul, South Korea). 


\subsection{Instruments and procedure}

For the modification of mineral coal, a THERMOLYNE horizontal oven (THERMO Sci, Waltham, MA, USA) with a tube of refractive ceramic with temperature control and a K type thermocouple was used. Samples were carbonized in inert atmosphere of $99.99 \%$ purity $\mathrm{N}_{2}$ (Oxiquim, Concepcion, Chile) at a flow of $150 \mathrm{~mL} \mathrm{~min}{ }^{-1}$ at a temperature of $750^{\circ} \mathrm{C}$ with residence time of $1 \mathrm{~h}$.

The surface of the Huitrero seam was modified by means of thermo chemical oxidation processes: in the first process, $4 \mathrm{~g}$ were put in contact with $40 \mathrm{~mL}$ of ammonium sulfate solution $\left(\mathrm{NH}_{4}\right)_{2} \mathrm{~S}_{4} \mathrm{O}_{8} 0,2 \mathrm{~mol} \mathrm{~L}^{-1}$ (Sigma Aldrich, St. Louis, USA) during $18 \mathrm{~h}$. After finishing the experiment, it was washed with abundant ultrapure water, filtered and dried at $105^{\circ} \mathrm{C}$. In the second oxidation phase, $3.4 \mathrm{~g}$ of oxidized carbon were put in contact with $175 \mathrm{~mL}$ of $0.2 \mathrm{~mol} \mathrm{~L}^{-1}$ $\mathrm{H}_{2} \mathrm{O}_{2}$ solution at room temperature during $24 \mathrm{~h}$.

\subsection{Characterization of mineral coals}

The original coal was characterized by means of the elementary analysis, proximal analysis, FTIR, petrographic analysis and electronic microscopy.

The procedure of the elementary analysis used in the study was conducted according to the ASTM D5373 [13], in a Leco model CHN2000 equipment (Leco Corp, St. Joseph, MI, USA).

The proximal analysis was carried out following the ASTM 5142 [14], in a LEGO TGA 60 Thermogravimetric Analyzer (SHIMADZU, Kyoto, Japan).

FTIR analysis was performed for both the original sample and those modified with the thermal treatment. In order to achieve this, a pellet of potassium bromide and carbon was prepared in a 1:100 proportion. The homogenized mixture was subjected to 3,000 lbs of pressure in order to obtain a pellet. Two equipment were used: Shimadzu Model 8400 (SHIMADZU, Kyoto, Japan) and Perkin Elmer Spectrum BX FT-IR System (Waltham, MA, USA).

For the petrographic analyses, circular test tubes were prepared. These contained the coal sample supported in an epoxic resin with hardener. Subsequently, samples were sanded and polished by using a Struers Labopol-5 polisher (Struers S/A, Ballerup, Denmark). A Nikon Eclipse LVD 100 metalographic microscope was used, coupled to a Nikon USB DS camera that captures the image and sends it to the computer for its processing (Nikon Corp, Tokyo, Japan).

For the morphological characterization of the original and modified coal employed, a JEOL Scanning Electron JSM-6380 V scanning electronic microscope was used (JEOL, Ltd, Tokyo, Japan).

For the determination of the surface groups of the coal selected in the preanalytical phase, the acid-base titration proposed by Boehm [15] was used.

\section{RESULTS AND DISCUSSION}

\subsection{Characterization of the original and modified mineral coal}

\subsubsection{Elementary and proximal analysis}

Table 1 shows the results obtained for both proximal and elementary analyses of the different mineral coal samples evaluated:

Table 1: Proximal and elementary analysis of coals from Mantos Negros Mine.

\begin{tabular}{|c|c|c|c|c|c|c|c|c|c|}
\hline \multirow{2}{*}{ Samples } & \multicolumn{3}{|c|}{$\begin{array}{c}\text { Proximal analysis } \\
\text { (\% dry basis) }\end{array}$} & \multicolumn{5}{c|}{$\begin{array}{c}\text { Elementary analysis } \\
\text { (\% dry basis) }\end{array}$} \\
\hline & $\begin{array}{c}\text { Humidity } \\
(\%)\end{array}$ & Ashes & $\begin{array}{c}\text { Volatile } \\
\text { matter }\end{array}$ & $\begin{array}{c}\text { Fixed } \\
\text { carbon }\end{array}$ & $\mathrm{C}$ & $\mathrm{H}$ & $\mathrm{N}$ & $\mathrm{O}$ & $\mathrm{S}$ \\
\hline CHS & 2.93 & 2.19 & 39.77 & 58.04 & 75.37 & 5.32 & 1.96 & 14.22 & 0.95 \\
\hline MA & 2.70 & 7.43 & 40.48 & 52.09 & 72.97 & 5.49 & 1.68 & 8.96 & 3.47 \\
\hline BS & 3.04 & 11.90 & 33.33 & 50.76 & 69.49 & 4.92 & 1.38 & 9.37 & 2.93 \\
\hline HS & 3.09 & 12.72 & 37.57 & 49.71 & 69.49 & 4.92 & 1.38 & 9.54 & 1.94 \\
\hline RS & 2.66 & 19.29 & 39.09 & 41.68 & 61.99 & 4.63 & 1.25 & 7.18 & 5.65 \\
\hline
\end{tabular}

In both, proximal and elementary analyses it can be observed that the major differences in terms of chemical composition are given by the percentage of ashes, volatile matter, fixed carbon and percentage of sulfur.

High percentages of volatile matter and low in fixed carbon indicate an incomplete carbonization process, generating low range carbons, and among them, sub-bituminous. Moreover, the high contents of volatile matter are responsible of the empty spaces existing in the structure of the coals subjected to thermal treatment, because by being subjected to high temperature, these are released. Therefore, carbon bonds that are free when the oxygen is released could better react in the adsorption processes, showing a variation of $2.85 \%$ of volatile matter among the different samples.

The greatest variation among samples is given for ashes, with $6.37 \%$, Ashes provide an idea about what type of minerals formed part of the coal. Thus, they can correspond to $\mathrm{SiO}_{2}$ (silicates), $\mathrm{Al}$ (aluminosilicates), $\mathrm{CO}_{3}{ }^{2-}$ (carbonates), $\mathrm{S}^{2-}$ (sulfurs), $\mathrm{SO}_{4}{ }^{2-}$ (sulfates), $\mathrm{Na}, \mathrm{Mg}, \mathrm{K}, \mathrm{Ca}, \mathrm{Pb}, \mathrm{Ca}$ and $\mathrm{P}$ among others. In the samples with greater percentage of ashes it would be expected that the mineral matter tends to be agglomerated, enabling an increase in the size of the pores, because they interact with carbonized molecules.

In studies of adsorption of liquid substances with coals, the relations $\mathrm{H} / \mathrm{C}$ and $\mathrm{O} / \mathrm{C}$ are factors that control the adsorption properties. It has been found that by increasing these atomic relations, the adsorption capacity of the coal decreases [16]. The analyzed coals present very little variation between them. For the $\mathrm{H} / \mathrm{C}$ relation there is an average of 0.077 , with a variation of $0.002 \%$. For the $\mathrm{O} / \mathrm{C}$ relation there is an average of 0.14 , with a variation of $0.03 \%$.

\subsubsection{Petrographic analysis}

Fig. 2 shows the presence of different macerals in the analyzed coals in both white and blue light.

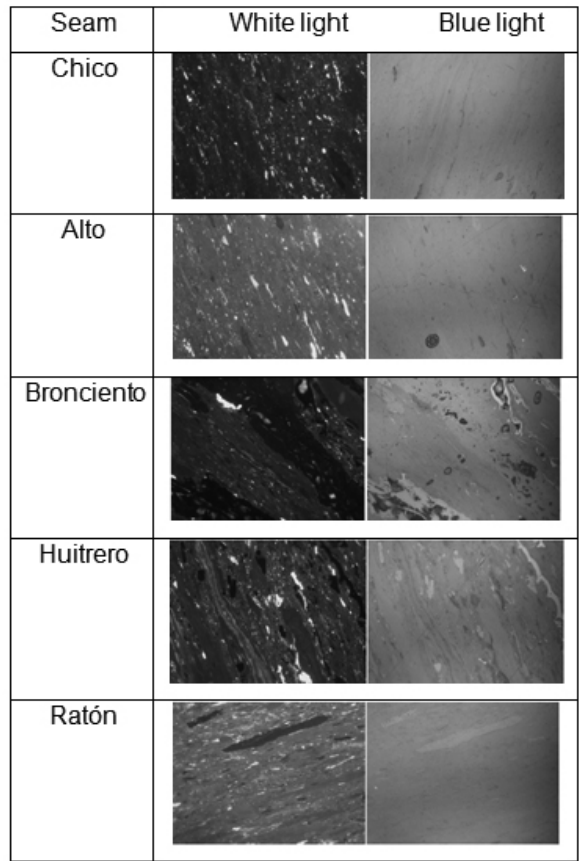

Figure 2: Macrographs obtained for the study of macerals in the mineral coals from the different seams for both White and blue Light 
The coal Petrographic analysis provides information about range, maceral composition, microlithotypes and distribution of minerals in coal (ASTM D338, 1991) [17], besides the fact of being a tool that helps to understand the origin and formation of coal, just like its characteristics and nature. In general, the presence of three macerals can be found: vitrinite, liptinite and inertinite, and each one can provide the possible origin of the studied coal.

In this study, a qualitative analysis of the macerals present in the coal was performed. In all coals it can be observed that the predominant maceral group corresponds to vitrinite, represented by a homogeneous gray band to blue light, which is very usual in this type of analyses. In the cases of Chico and Alto seams, vitrinite is mainly observed, whereas the liptinite and inertinite content is almost inexistent. In Bronciento seam the presence of mineral material becomes evident at both light and blue light, and the minerals show a reflectance similar or greater than inertinite. Unlike the previous seams, Raton seam presents a higher proportion of inertinite than liptinite, but vitrinite is still the most abundant maceral.

\section{FTIR}

Fourier Transform - infrared spectroscopy of the original and carbonized coals are presented in Fig. 3 and Fig 4. Fig. 3 shows the FTIR spectrum of the analyzed coal samples. The spectra found indicate a great variety of vibrations. Groups of $-\mathrm{NH}-\mathrm{NH}_{2}-\mathrm{OH}$ can be found in band $1\left(3392 \mathrm{~cm}^{-1}\right)$. Bands between 2850 and $2950 \mathrm{~cm}^{-1}$ are characteristic of the groups $\mathrm{CH}_{2}$ and $\mathrm{CH}_{3}$ (band 2 and 3). The groups $-\mathrm{C}=\mathrm{O}-\mathrm{O}-\mathrm{CO}, \mathrm{C}=\mathrm{C}-\mathrm{OH}$ (aromatic) and $\mathrm{C}=\mathrm{O}, \mathrm{C}=\mathrm{C}$, aromatics -OH (between 1580-1800 $\mathrm{cm}^{-1}$ ) can be also found. Other aromatic groups are found between 600 and $920 \mathrm{~cm}^{-1}$. The presence of mineral groups can be observed between the bands of $460-540 \mathrm{~cm}^{-1}$, and between 1000 and 1050 $\mathrm{cm}^{-1}$.

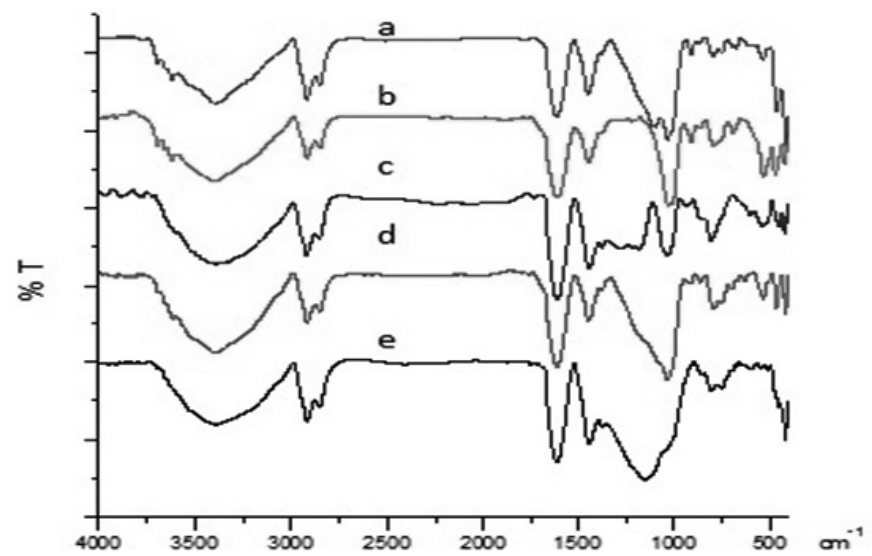

Figure 3: Compiled of FT - IR spectra of mineral coals from Lebu, with washing treatment with distilled water at $60^{\circ} \mathrm{C}$. a) RS, b) $\mathrm{HS}$, c) MC, d) BS and e) AS

In Fig. 4, little definition of the spectra from 2,000 to $4,000 \mathrm{~cm}^{-1}$ approximately are observed. A large band in the zone of the oxygenated function groups such as hydroxyl, carbonyl and carboxyl, among others can be seen. In this zone, a band for wave numbers between 3200 and $3500 \mathrm{~cm}^{-1}$ could be found. This band corresponds to stretching vibrations of the $\mathrm{O}-\mathrm{H}$ functional group. On the other hand, this band becomes wider in the oxidized coals. Similarly, in some of the spectra there are small intensity peaks that correspond to the functional groups $\mathrm{C}-\mathrm{H},-\mathrm{CH}_{2},-\mathrm{CH}_{3}$. In addition, a series of peaks between wave numbers 1,400 and $1,700 \mathrm{~cm}^{-1}$ of moderate intensity can be also observed. These can be attributed to enlargements of the functional groups of $\mathrm{C}=\mathrm{O}$ and $\mathrm{C}=\mathrm{C}$ types, which can correspond to the presence of acetones, esters, aldehydes and carboxylic acids. The change of the spectra can be explained by the pre-oxidizing process with air at $185^{\circ} \mathrm{C}$ applied to the samples. This process is applied to avoid plasticization of the coal in the carbonization process (Fig. 4).

3.1.3 Scanning Electronic Microscopy (SEM)

Electronic macrographs were obtained from the studied seams. By means of SEM analysis of the mineral matter in coal (Fig. 5) an irregular morphology of the coal particles was observed, as well as the porosity by seeing the fully smooth texture. The presence of mineral matter is observed and the incomplete carbonization process can be also evidenced.

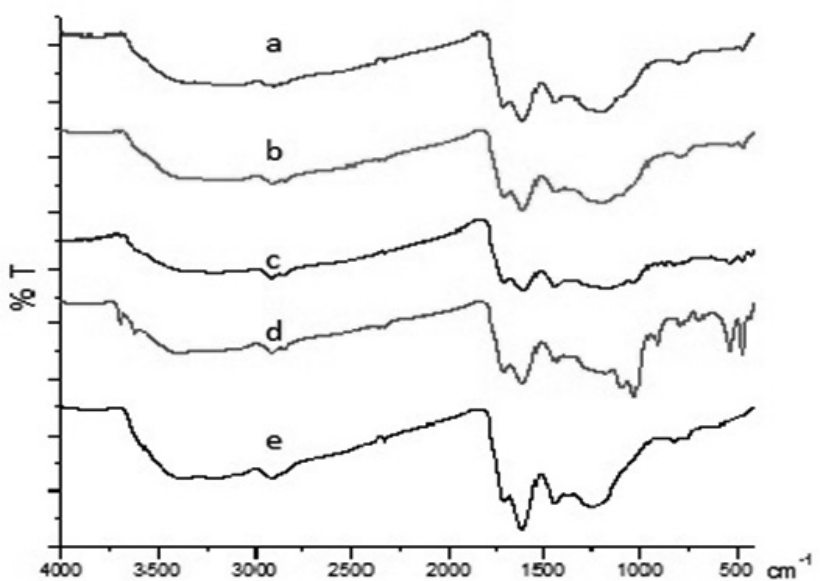

Figure 4: Compiled of the FTIR spectra for mineral coal samples exponed the thermal treatment in atmosphere of $\mathrm{N}_{2}$ at $150 \mathrm{~mL} \mathrm{~min}^{-1}$ at temperatures of $750^{\circ} \mathrm{C}$ and residence time of 60 minutes: a) BS, b) MC, c) HS, d) RS and e) AS. a)

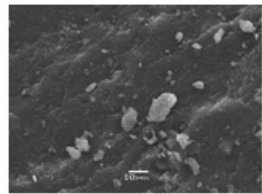

d)

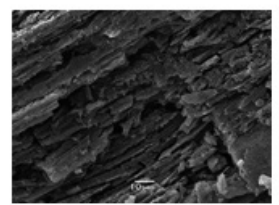

b)
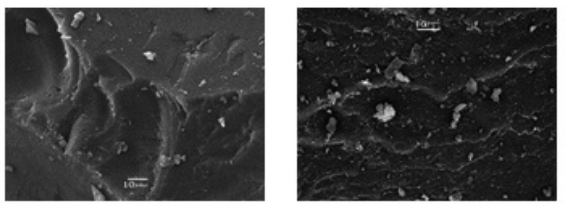

e)
Figure 5: SEM micrographs of mineral coals: a) Ratón seam, b) Huitrero seam, c) Chico seam, d) Bronciento seam, and e) Alto seam.

In Fig. 6 the SEM analysis with 100x magnification, for the carbonized coals is shown. The presence of porosity can be observed, evidencing a significant increase of the specific surface of the coals by being subjected to a thermal treatment with $\mathrm{N}_{2}$.

This increase of the specific surface of the coals can be evidenced in the increase of the iodine index, analysis that provides an estimated value of the specific surface presented by the carbonized coals.
a)CRS

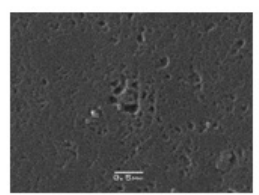

d)CBS

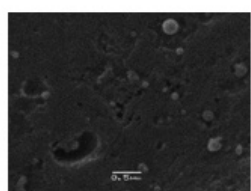

b) $\mathrm{CHS}$

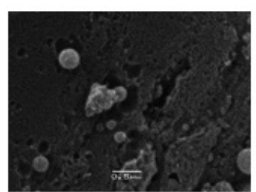

e)CAS

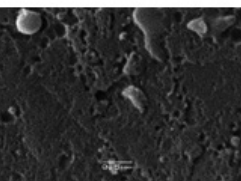

Figure 6: SEM micrographs of mineral coals: a) Raton seam carbonized, b) Huitrero seam carbonized, c) Chico seam carbonized, d) Bronciento seam carbonized, e) Alto seam carbonized. Treatment with current $\mathrm{N}_{2}$ at $150 \mathrm{~mL}$ min 1 , temperature of $750^{\circ} \mathrm{C}$, and residence time of 60 minutes, $100 \mathrm{x}$ magnification. 


\subsubsection{Iodine index analysis (II)}

Iodine number also called iodine value or iodine index, is an index of the surface are of an activated coal, parameter for characterizing activated carbon performance. This is due to the fact that iodine is adsorbed very efficiently in a monomolecular layer and its size allows to be homed even in the smallest pores in which the adsorption is taking place. Therefore, the amount of iodine adsorbed is proportional to the coal area. It is expressed in $\mathrm{mg}$ of iodine adsorbed by gram of coal ( $\left.\mathrm{mg} \mathrm{I}_{2} \mathrm{~g}^{-1}\right)$. It should be noted that this value is approximately equal to the surface area obtained through the BET method of $\mathrm{N}_{2}$ adsorption, expressed in $\mathrm{m}^{2} \mathrm{~g}^{-1}$ of coal (data no shown).

Table 2 shows the values obtained for the iodine index and their carbonized.

Table 2: Results for the Iodine number analysis with their respective standard deviation for the different seams and their carbonized

\begin{tabular}{|c|c|c|}
\hline Seam & $\begin{array}{c}\text { Average } \\
\mathrm{mg} \mathrm{I}_{2} \mathrm{~g}^{-1} \\
\text { coal }\end{array}$ & $\begin{array}{c}\text { Average } \\
\mathrm{mg} \mathrm{I}_{2} \mathrm{~g}^{-1} \text { carbonized }\end{array}$ \\
\hline Chico & $2.5 \pm 0.6$ & $255 \pm 13$ \\
\hline Raton & $3.9 \pm 0.5$ & $83 \pm 7$ \\
\hline Alto & $1.6 \pm 0.5$ & $205 \pm 15$ \\
\hline Huitrero & $2.6 \pm 0.3$ & $177 \pm 8$ \\
\hline Bronciento & $1.1 \pm 0.1$ & $66 \pm 6$ \\
\hline
\end{tabular}

\subsubsection{Boehm titration procedure}

In Table 3 the results obtained by means of the titration method proposed by Boehm are presented for some samples. Thus, the content of acid nature groups due to carboxylic Group is quantified.

Table 3: Results for Boehm titration and identification of carboxyl active sites of the activated coal and Huitrero seam (with and without oxidizing). CA : Activated coal, HS: Huitrero seam, PA : ammonium persulfate, PH: hydrogen peroxide, Csa: Concentration of active sites $\mathrm{mmol} \mathrm{g}^{-1}$

\begin{tabular}{|c|c|c|c|c|}
\hline Coal & $\begin{array}{c}\text { Csa 1 } \\
\left(\mathrm{mmol} \mathrm{g}^{-1}\right)\end{array}$ & $\begin{array}{c}\mathrm{Csa} 2 \\
\left(\mathrm{mmol} \mathrm{g}^{-1}\right)\end{array}$ & $\begin{array}{c}\text { Csa 3 } \\
\left(\mathrm{mmol} \mathrm{g}^{-1}\right)\end{array}$ & $\begin{array}{c}\text { Average } \\
\left(\mathrm{mmol} \mathrm{g}^{-1}\right)\end{array}$ \\
\hline CA & 2.194 & 2.011 & 2.092 & $2.09 \pm 0.09$ \\
\hline HS & 2.289 & 2.106 & 2.062 & $2.06 \pm 0.12$ \\
\hline CA PA+PH & 2.515 & 2.275 & 2.264 & $2.26 \pm 0.14$ \\
\hline HS PA+PH & 2.530 & 2.391 & 2.235 & $2.24 \pm 0.15$ \\
\hline
\end{tabular}

The concentration of active sites increases in function of the treatment with ammonium persulfate and hydrogen peroxide, indicating that there is no oxidation in the surface. This oxidation may influence on the adsorption chemistry of the coals, making their surface more selective.

\section{CONCLUSIONS}

We have performed a chemical characterization of coal from the province of Arauco, as well as its derivatives subjected to carbonization and oxidative treatment with persulfate. The results show that the carbon and oxygen contents are higher in lower seams, as Chico Seam and Alto Seam and these contents decrease below $70 \%$ for upper seams, may be due to the high pressures to which they have been subjected. Also, higher carbon and oxygen content seem to lower presence of sulfur is observed, as shown in the case Chico Seam.

Petrographic analysis shows that for all seams studied, vitrinite is the most abundant maceral found, having small variations between different seams and there are also small amounts of inertinite and liptinite.

The FTIR analysis helps to illustrate the functional groups which are present for each type of seams, being in different proportions the groups - $\mathrm{CH} 2$, $-\mathrm{CH} 3,-\mathrm{C}=\mathrm{O}-\mathrm{O}-\mathrm{CO}, \mathrm{C}=\mathrm{C}-\mathrm{OH}$ (aromatic) and $\mathrm{C}=\mathrm{O}, \mathrm{C}=\mathrm{C},-\mathrm{OH}$ aromatics. After the carbonization process in the presence of $\mathrm{N} 2$, percentage of $\mathrm{C}=\mathrm{O}$ and $\mathrm{C}=\mathrm{C}$ groups increases, which becomes apparent by the increase of the bands corresponding to these functional groups.

Thanks to SEM analysis it was observed an increase of the surface between the different types of seams before and after heat treatment, which is consistent with increased iodine number and similar results reported, when BET method is used for determining surface area.
These results, together to those obtained with oxidative treatment, using ammonium persulfate, show an increase in surface area, which may lead to the use of this material as an adsorbent for different applications, such as electrochemical, which is already working in the research group.

\section{AKNOWLEDGEMENTS}

Financial Support from Conicyt, Grant 78111107 Industrial Thesis, Innovabiobio Cod 97, Fondecyt 1120815 \& 11130388 is gratefully acknowledged.

\section{REFERENCES}

1. Collao, S., Oyarzun, R., Palma, S., and Pineda, V., , Stratigraphy, palynology, andgeochemistry of the lower Eocene coals of Arauco, Chile: International Journal of Coal Geology, 1987, 7, 195-208.

2. Hackley P., Warwick P., Alfaro G., and Cuebas R. World Coal Quality Inventory: South America. U.S. Geological Survey Open-File Report 2006-1241

3. Helle, S., Alfaro, G.H., Kelm, U., and Tascon, J.M.D.Mineralogical and chemical characterization of coals from southern Chile. International Journal of Coal Geology, 2000, 44, 85-94.

4. Mercado Nacional e Internacional del Carbón Colombiano. Unidad de Planificación Minero Energética. ISBN 958-97750-7 UPME, 2006.

5. Marten G., Asensio M., Font R., Marcilla A. Steam-Activated Carbons from a Bituminous Coal in a Continuous Multistage Fluidized Bed Pilot Plant. Carbon 1996, 34, 1515-1520.

6. Strelko V. V., Stavitskaya S. S., Tsyba N. N., Lysenko A. A., Zhuravskii S. V., Goba V. E. Directed Modification of Carbons of Varied Origin and Chemical Nature of the Surface in Order to Control Their Catalytic Activity. Russian Journal of Applied Chemistry, 2007, 80, 389-396

7. Zhang J., Gong L., Sun K., Jiang J., Zhang X. Preparation of Activated Carbon from waste Camellia Oleifera shell for Supercapacitor application. Journal Solid State electrochem, 2012, 16, 2179-2186.

8. Guo P., Yi G., Zhibin L., Yuqian C., Zhao X.S. Preparation of Sucrosebased Microporous Carbons and their Application as Electrode Material for Supercapacitors. Microporous and Mesoporous Materials, 2012, 156, 176-180.

9. Sánchez J., Stoeckli F., Centeno T. The role of the Electric Conductivity of Carbons in the Electrochemical Capacitor Performance. Journal of Electroanalytical Chemistry, 2011, 65, 176-181.

10. Flores-Álvarez J. M., González I., García-de la Rosa L.A., Mancilla-Peña F., Reyes-Gómez J. Carbon Paste Electrodes modified with Biosolids, Soils and Biocomposites utilized to Study the Interaction between Organic Matter and Copper. Journal of Environmental Management, 2011, 92, 448456.

11. Ji S., Jong Gu K., Tae-Sung B., Hye-Ryeon Y.,Young-Seak L. Surface Modification of Electrospun Spherical Activated Carbon for a HighPerformance Biosensor Electrode. Sensors and Actuators B, 2011, 158, $151-158$.

12. Ahumada E. Obtención de un Carbón Activo Impregnado de Hierro (II) para ser usado en Tratamientos de agua que contienen Compuestos Fenólicos. Revista Semestral Pharos Artes, Ciencia y Tecnología. Universidad de las Américas, 2004, 21-36

13. ASTM D5373-14e1, Standard Test Methods for Determination of Carbon, Hydrogen and Nitrogen in Analysis Samples of Coal and Carbon in Analysis Samples of Coal and Coke, ASTM International, West Conshohocken, PA, 2014.

14. ASTM D5142-09, Standard Test Methods for Proximate Analysis of the Analysis Sample of Coal and Coke by Instrumental Procedures (Withdrawn 2010), ASTM International, West Conshohocken, PA, 2009.

15. Boehm H.P. Surface oxides on carbon and their analysis: a critical assessment. Carbon, 2002, 40, 145-149.

16. Yan, C.; Yan, Y.; Liu, M.; Nie, M. y Zhou, J.L. Phenanthrene sorption to Chinese coal: Importance of coal's geochemical properties. Journal of Hazardous Materials. 2011, 192, 86-92

17. ASTM D388-92a, Classification of Coal by Rank, ASTM International, West Conshohocken, PA, 1992. 